\title{
La cooperación educativa no universitaria entre España y Marruecos
}

The non-university educational cooperation between Spain and Morocco

Siham ZEBDA ${ }^{1}$

Universidad de Cádiz

siham.zebda@uca.es

https://orcid.org/0000-0003-3817-1860

Recibido 16/09/2020. Aceptado 22/5/2021

Para citar este artículo: Siham ZEBDA (2021): "La cooperación educativa no universitaria entre España y Marruecos" en Revista de Estudios Internacionales Mediterráneos, 30, pp. 124-147.

Para acceder a este artículo: https://doi.org/10.15366/reim2021.30.007

\section{Resumen:}

La cooperación educativa no universitaria ocupa un lugar importante en la agenda bilateral hispanomarroquí como lo refleja su tratamiento en las once Reuniones de Alto Nivel celebradas entre España y Marruecos así como por los convenios y tratados firmados entre ambas partes. Esta cooperación se concreta en el Programa de Enseñanza de la Lengua Árabe y la Cultura Marroquí (LACM) en los colegios españoles y en la enseñanza del español en Marruecos, tanto en el marco del sistema educativo nacional marroquí como en la red de centros educativos españoles en Marruecos. En este trabajo pretendemos realizar una radiografía de esta cooperación haciendo un balance de los diferentes programas y propuestas recogidas en las Reuniones de Alto Nivel.

Palabras clave: cooperación educativa/ España/ Marruecos/ reuniones de alto nivel/LACM/

\footnotetext{
${ }^{1}$ Profesora Sustituta Interina de Derecho Internacional Público y Relaciones Internacionales de la Universidad de Cádiz. El presente trabajo forma parte de las líneas de trabajo del Grupo de Investigación «Centro de Estudios Internacionales y Europeos del Área del Estrecho»-SEJ 572-, del Plan Andaluz de Investigación, del que es Investigador Responsable el Dr. Alejandro del Valle Gálvez, Catedrático de Derecho Internacional Público y Relaciones Internacionales de la Universidad de Cádiz y del Centro de Excelencia de la Comisión Europea "Inmigración y Derechos Humanos en las Fronteras Exteriores Europeas" 2017-2021.
} 


\begin{abstract}
:
Non-university education cooperation programs occupy an important place in the SpanishMoroccan bilateral agenda, as reflected in the treatment of the eleven High-Level Meetings held between Spain and Morocco, as well as in the agreements and treaties signed between both parties. This cooperation takes place in the frame of the Teaching Program of the Arabic Language and Moroccan Culture (ALMC) in Spanish schools and in the teaching of Spanish in Morocco, both within the framework of the Moroccan National Educational System and in the network of Spanish Educational Centres in Morocco. In this paper, we intend to make a diagnostics of this cooperation, taking into account the different programs and proposals collected in the High Level Meetings between Morocco and Spain.
\end{abstract}

Keywords: Educational Cooperation/ Spain/ Morocco/ High Level Meeting/ ALMC/

\title{
Introducción
}

La educación no universitaria es uno de los ámbitos donde se concreta la cooperación bilateral entre España y Marruecos. Junto a los acuerdos bilaterales suscritos entre ambos países (Del Valle y Torrejón, 2013), esta cuestión ha estado presente en todas las Reuniones de Alto Nivel (RAN) celebradas entre España y Marruecos desde la entrada en vigor en 1993 del Tratado de Amistad, Buena Vecindad y Cooperación ${ }^{2}$. Desde entonces se han celebrado once RAN $\left(1993^{3}\right.$ y $1996^{4}$ en Rabat, $1997^{5}$ en Madrid, $1998^{6}$ en Rabat, $1999^{7}$ en Madrid, $2003^{8}$ en Marrakech, $2005^{9}$ en Córdoba y Sevilla, $2007^{10}$ en Rabat, $2008^{11}$ en Madrid, 2012 ${ }^{12}$, en Rabat, $2015^{13}$ en Madrid).

La cooperación educativa no universitaria entre España y Marruecos se concreta en dos ámbitos principales. Por un lado, en la enseñanza de la lengua española en Marruecos, tanto en el sistema educativo marroquí, como a través de la red de colegios españoles que dependen del Ministerio de Educación español. Por otra parte, la cooperación bilateral se lleva a cabo a través del Programa

\footnotetext{
2 Tratado de Amistad, Buena Vecindad y Cooperación entre el Reino de España y el Reino de Marruecos, hecho en Rabat, el 4 de julio de 1991, BOE, no , 49, de 26 de febrero de 1993, https://www.boe.es/buscar/doc.php?id=BOE-A-1993-5422 [consulta: 12 de abril de 2021].

3 DEL VALLE GÁLVEZ, José Alejandro. TORREJÓN RODRÍGUEZ, Juan Domingo (2013): España y Marruecos tratados, declaraciones y memorandos de entendimiento (1991-2013), Cádiz, Servicio de Publicaciones de la Universidad de Cádiz pp. 251-255.

${ }^{4}$ Ibid, pp. 255-266.

${ }^{5}$ Ibid, pp. 266-276.

6 Ibid, pp. 276-288.

${ }^{7}$ lbid, pp. 288-294.

${ }^{8}$ Ibid, pp. 294-303.

${ }^{9}$ Ibid, pp. 303-318.

${ }^{10}$ lbid, pp. 318-329.

11 lbid, pp. 329-343.

12 TORREJÓN RODRIGUEZ, Juan Domingo. ZEBDA Siham (2013): “Reunión de Alto Nivel España-Marruecos Rabat, Octubre 2012", Paix et Sécurité Internationales, 1, pp. 177-201.

${ }^{13}$ https://www.lamoncloa.gob.es/presidente/actividades/Documents/2015/2015\%20ESP\%20declaraci\%c3\%b3n\%20XI. pdf [consulta: 12 de abril de 2021].
} 
de Enseñanza de Lengua Árabe y Cultura Marroquí (LACM) ${ }^{14}$ introducido en el sistema educativo español en algunos centros con un número considerable de alumnos marroquíes.

El presente trabajo tiene como objetivo valorar la implantación de la enseñanza del español en Marruecos y del árabe en España y el reflejo de este ámbito de la cooperación bilateral en los acuerdos adoptados en las Reuniones de Alto Nivel.

Un indicador para determinar el estado de las relaciones entre los dos países es el nivel de la cooperación bilateral. En el caso de España y Marruecos la cooperación educativa no universitaria ha sido considerada como un ámbito prioritario. Un repaso a las declaraciones oficiales muestra como ambos Estados se felicitan periódicamente por los esfuerzos llevados a cabo para fomentar la enseñanza del español en Marruecos y del árabe en España. Este artículo analiza el alcance y grado de aplicación en la práctica de los acuerdos firmados en este ámbito.

El aprendizaje del idioma es considerado un primer paso para el entendimiento de ambos pueblos, además el árabe para el alumnado de origen marroquí en España es necesario para su integración en España. España y Marruecos, insisten en todas las RAN -consideradas como un termómetro pare medir el estado de las relaciones hispano-marroquíes- sobre la necesidad de reforzar la enseñanza del español en Marruecos y del árabe en España, con el objetivo de aumentar la comprensión y el entendimiento entre sus sociedades contribuyendo a la difusión de sus patrimonios culturales y a la integración de sus ciudadanos. Los convenios firmados entre España y Marruecos entre 2000 y 2019 han permitido impulsar la implantación lingüística del español en Marruecos y del árabe en España en el marco de la enseñanza oficial primaria. Sin embargo esta implantación no ha sido idéntica ni uniforme en ambos países.

La primera parte de nuestro trabajo tiene como objetivo conocer el lugar que ocupa la educación no universitaria en la agenda hispano-marroquí a través del análisis de los tratados y acuerdos existentes entre España y Marruecos sobre la cooperación educativa. Igualmente busca constatar la importancia que se da a la cooperación educativa entre España y Marruecos a través de las once RAN celebradas hasta el momento de redactar este trabajo, repasando en cada una de ellas el lugar que ocupa la enseñanza del árabe en España y del español en Marruecos.

En la segunda parte, realizaremos un recorrido histórico sobre la evolución de los Programas de Lengua y Cultura de Origen en Europa (ELCO) que con las primeras migraciones marroquíes a Europa tenían como objetivo facilitar el retorno de los inmigrantes a su país de origen y que, con el paso del tiempo, se convirtieron en una herramienta para alcanzar una educación equilibrada.

En el tercer apartado, trataremos la implantación del Programa de Enseñanza de la Lengua Árabe y la Cultura Marroquí (LACM) en España que tiene su origen en la ELCO como consecuencia del aumento del número de alumnado marroquí o de padres marroquíes en España.

En el último apartado, abordaremos la situación del español en Marruecos realizando un recorrido histórico hasta el contexto socio-lingüístico actual. El repaso de esta evolución permite entender mejor la enseñanza del español dentro del sistema educativo marroquí así como su papel en la red de colegios españoles dependientes del Ministerio de Educación español.

\section{Las relaciones educativas entre España y Marruecos}

\section{Los tratados culturales}

La cooperación en materia educativa se remonta a la independencia de Marruecos en 1956 y ha ido evolucionando desde entonces. A principios de los años 2000 Marruecos era:

"el primer receptor de becas españolas para estudios e investigación, en número de Institutos Cervantes, en centros de enseñanza públicos españoles, en número de profesores

\footnotetext{
${ }^{14}$ http://www.mecd.gob.es/dms-static/2e685421-9eda-4bf7-93cb-c1ac8737c999/lacm-pdf.pdf [consulta: 12 de abril de 2021].
} 
y alumnos impartiendo y enseñando español respectivamente, en colaboración universitaria y asesoría lingüísticas" (González del Miño, 2005: 68).

La transformación de España en un país de inmigración tras la incorporación a la Comunidad Europea en 1986 diversificó la agenda bilateral. El establecimiento de una importante comunidad de inmigrantes marroquíes hizo que la escolarización de los hijos de los marroquíes residentes en España ocupara desde entonces un importante lugar en la agenda bilateral hispano-marroquí.

La cooperación educativa entre España y Marruecos se fundamenta en los vínculos históricos y culturales y en la tradicional amistad entre ambos pueblos, el español y el marroquí que pretenden aumentar la comprensión entre ellos, profundizar el conocimiento, la comprensión y el entendimiento por medio de la difusión de sus respectivas lenguas y patrimonio culturales y adaptar esta cooperación a las necesidades de los dos países ${ }^{15}$.

Pero eso no siempre fue así, el primer Convenio Cultural Hispano-Marroquí ${ }^{16}$ que trató el tema de la educación, firmado en 1957, no lo consiguió a pesar de que tuvo como objetivo abrir una nueva página de amistad entre España y Marruecos después de la época del Protectorado. Por una parte, el resentimiento por la época colonial no hizo ver con buenos ojos la iniciativa española en Maruecos, y por otra parte, la incomprensión durante mucho tiempo no benefició a ninguna de las partes. (Benyaya, 2007: 170).

Hubo que esperar más de dos décadas para que las relaciones educativas entre España y Marruecos adquirieran un nuevo impulso con la firma del Convenio Hispano-Marroquí de Cooperación Cultural de 1980 que entró en vigor en $1985^{17}$. Este Convenio estableció por primera vez las líneas generales de la cooperación en este ámbito estableciendo un régimen de reciprocidad por el que los hijos de los nacionales de cada parte podían acceder al sistema educativo en condiciones de igualdad. También preveía la enseñanza del árabe en los colegios españoles y dejaba la puerta abierta a la apertura de nuevos establecimientos educativos españoles en Marruecos conforme al programa de la educación española.

El Tratado de Amistad, Buena Vecindad y Cooperación de $1991^{18}$ recogía en su artículo 9 el compromiso de ambos países para "brindar una particular atención a la enseñanza del idioma y de la civilización árabes en España y de la lengua y de la civilización españolas en Marruecos".

\footnotetext{
${ }^{15}$ Aplicación provisional del Convenio de Asociación Estratégica en materia de Desarrollo y de Cooperación Cultural, Educativa y Deportiva entre el Reino de España y el Reino de Marruecos, hecho "ad referendum" en Rabat el 3 de octubre de 2012, BOE, no 182, de 31 de julio de 2013. https://www.boe.es/buscar/doc.php?id=BOE-A-2013-8379 [consulta: 11 de abril de 2021].

${ }^{16}$ Referenciado en Convenio de Cooperación Cultural entre el Gobierno de España y el Gobierno del Reino de Marruecos. Hecho en Rabat el 14 de octubre de 1980, BOE n-243. https://www.boe.es/buscar/doc.php?id=BOE-A1985-20897 [consulta: 11 de abril de 2021].

${ }^{17}$ Convenio de Cooperación Cultural entre el Gobierno de España y el Gobierno del Reino de Marruecos. Hecho en Rabat el 14 de octubre de 1980, Boletín Oficial del Estado (BOE), no 243, de 10 de octubre de 1985. https://www.boe.es/buscar/doc.php?id=BOE-A-1985-20897 [consulta: 11 de abril de 2021].

${ }^{18}$ Este Tratado dio un impulso a las relaciones hispano-marroquíes en todos los ámbitos ya que se considera el acuerdo marco de esas relaciones fue el primer tratado de ese tipo con un país magrebí.
} 
En 2012 el acuerdo de 1980 fue actualizado con la firma de un nuevo Convenio de Asociación Estratégica en materia de Desarrollo y de Cooperación Cultural, Educativa y Deportiva ${ }^{19}$, firmado en el marco de la X Reunión de Alto Nivel celebrada en Madrid.

\section{La cooperación educativa en las Reuniones de Alto Nivel}

El Tratado de Amistad, Buena Vecindad y de Cooperación firmado en 1991 introducía por primera vez la celebración periódica de Reuniones de Alto Nivel (RAN) entre los Gobiernos de ambos países con el objetivo de hacer un seguimiento regular de las relaciones bilaterales (Hernando de Larramendi y Mañé, 2009) ${ }^{20}$.

Aunque se preveía que éstas tuvieran una periodicidad anual, el ritmo de celebración de las RAN ha sido irregular. En los 27 años transcurridos desde la entrada en vigor del Tratado en 1993 sólo se han celebrado once reuniones, la última en 2015.

Los temas tratados en las Reuniones de Alto Nivel han evolucionado. Aunque la primera reunión celebrada en Rabat en 1993 tuvo una agenda temática limitada (Zebda, 2015: 227), la cooperación en materia educativa fue uno de los pocos ámbitos abordados. Por una parte, el Gobierno de España manifestó su interés por ampliar la red de establecimientos docentes españoles en Marruecos con la creación de un nuevo centro educativo en Rabat. Por otra parte, ambos países mostraron su interés por el desarrollo de los cursos de Lengua Árabe y Cultura Marroquí en el sistema educativo general en la Comunidad Autónoma de Madrid donde se había iniciado su implantación ${ }^{21}$.

La II RAN no se celebró hasta tres años después en Rabat en 1996 a causa de las tensiones provocadas por las negociaciones de renovación del tercer acuerdo pesquero Marruecos-CE, del que se beneficiaban sobre todo pescadores españoles. Las negociaciones del acuerdo pesquero de 1995 fueron una de las más complicadas (El Houdaigui, 2003: 121) porque hubo un tira y afloja con el que cada parte intentó garantizarse un resultado ventajoso. Finalmente, las dos partes tuvieron que hacer concesiones y llegaron a firmar el acuerdo a finales de 1995.

La reunión de Alto Nivel de 1996 permitió impulsar de nuevo las relaciones. La cuestión de las percepciones reciprocas y la necesidad de trabajar en la eliminación de los recelos mutuos y prejuicios colectivos, que impedían un mejor entendimiento entre las sociedades de ambos países fue uno de los temas que estuvo presente en el orden del día. La enseñanza primaria y secundaria también ocuparon una parte importante de la agenda tal y como recoge la declaración conjunta aprobada al final de la reunión en la que se subrayó:

A) la importancia del desarrollo de la lengua árabe en España ampliando la experiencia desarrollada hasta entonces en la Comunidad de Madrid;

\footnotetext{
${ }^{19}$ Aplicación provisional del Convenio de Asociación Estratégica en materia de Desarrollo y de Cooperación Cultural, Educativa y Deportiva entre el Reino de España y el Reino de Marruecos, hecho "ad referendum" en Rabat el 3 de octubre de 2012, BOE, no 182, de 31 de julio de 2013. https://www.boe.es/buscar/doc.php?id=BOE-A-2013-8379 [consulta: 11 de abril de 2021].

20 "Las Altas Partes Contratantes, deseosas de reforzar y potenciar los lazos que las unen, se proponen establecer un marco de contactos políticos bilaterales más acorde con el nivel de cooperación y concertación al que aspiran. A tal efecto, acuerdan institucionalizar lo siguiente:

1. Reunión anual de Alto Nivel entre los Jefes de Gobierno de ambos países, en España y en Marruecos, alternativamente. Se celebrarán encuentros entre los Ministros y Secretarios de Estado al objeto de preparar adecuadamente la citada Reunión". Artículo 1 del Tratado de amistad, buena vecindad y cooperación entre el Reino de España y el Reino de Marruecos.

${ }^{21}$ Comunicado conjunto hispano-marroquí al término de la I Reunión de Alto Nivel (Madrid, 3-4 de diciembre de 1993). DEL VALLE GÁLVEZ, José Alejandro. TORREJÓN RODRÍGUEZ, Juan Domingo (2013): España y Marruecos tratados, declaraciones y memorandos de entendimiento (1991-2013), Cádiz, Servicio de Publicaciones de la Universidad de Cádiz pp. 251-255.
} 
B) la continuación con el desarrollo de la oferta de lengua española en la enseñanza secundaria marroquí en el conjunto de las provincias del reino;

C) la creación de un grupo mixto de trabajo para la experimentación en los institutos marroquíes de secciones bilingües «opción española» con objeto de llegar a un bachillerato de tipo internacional.

D) la continuidad de los intercambios de información y de experiencias pedagógicas respecto de los sistemas educativos de ambos países. En este terreno el Ministerio de Educación Nacional marroquí demostró su interés por beneficiarse de la experiencia española en el ámbito de la organización pedagógica, de la enseñanza de las materias científicas y técnicas y las técnicas de desarrollo de los curricula ${ }^{22}$.

Además, en el marco de esta Reunión se firmó un Acuerdo por el que Marruecos cedió un edificio escolar a España destinado a la creación de un nuevo colegio español en Rabat ${ }^{23}$.

En la III RAN celebrada en 1997 en Madrid, los Gobiernos de ambos países se limitaron a reiterar su compromiso de proseguir con el fomento de la enseñanza de la lengua árabe en España y de la española en Marruecos ${ }^{24}$.

En la IV RAN celebrada en Rabat en 1998, se subrayó la amplitud de la cooperación bilateral en los sectores educativos a la que contribuían los diez establecimientos escolares españoles y un número importante de consejeros lingüísticos para el apoyo técnico a la enseñanza del español en el sistema educativo marroquí. Ambos gobiernos expresaron su interés por el desarrollo de la enseñanza de la lengua española en el sistema educativo marroquí y su ampliación a la enseñanza fundamental y para una mejora cualitativa mediante la utilización de nuevas tecnologías educativas. Sin embargo en la declaración no se hizo ninguna mención a la enseñanza de la lengua árabe en España ${ }^{25}$.

En la V RAN celebrada en Madrid en 1999, en materia educativa solo se menciona la importancia que tiene la enseñanza de la lengua y cultura árabes para los marroquíes residentes en España ${ }^{26}$.

La siguiente reunión no se celebró hasta cuatro años después, debido a las tensiones entre ambos países por temas de inmigración y pesca, que culminaron con la crisis del islote de Perejil en julio de 2002 (Planet y Hernando de Larramendi 2005). En la VI RAN celebrada en Marrakech en 2003 fue reiterada la importancia de la lengua en el diálogo de culturas conviniéndose desarrollar la enseñanza del español en particular utilizando las redes de escuelas españolas en Marruecos ${ }^{27}$. Lo

\footnotetext{
${ }^{22}$ Declaración conjunta hispano-marroquí al término de la II Reunión de Alto Nivel (Rabat, 6 de diciembre de 1996). Ibid, pp. 255-266.

${ }^{23}$ Acuerdo por el que el Gobierno del Reino de Marruecos pone a disposición del Gobierno del Reino de España un edificio destinado a centro escolar, firmado «ad referendum» en Rabat el 6 de febrero de 1996, BOE, no 242 , de 7 de octubre de 1996. https://www.boe.es/diario boe/txt.php?id=BOE-A-1996-12097 [consulta: 11 de abril de 2021].

${ }^{24}$ Declaración conjunta hispano-marroquí al término de la III Reunión de Alto Nivel (Madrid, 5 de junio de 1997). DEL VALLE GÁLVEZ, José Alejandro. TORREJÓN RODRÍGUEZ, Juan Domingo (2013): España y Marruecos tratados, declaraciones y memorandos de entendimiento (1991-2013), Cádiz, Servicio de Publicaciones de la Universidad de Cádiz pp. 266-276.

${ }^{25}$ Declaración conjunta hispano-marroquí al término de la IV Reunión de Alto Nivel (Rabat, 27 de abril de 1998).lbid, pp. 276-288.

${ }^{26}$ Declaración final de la V Reunión de Alto Nivel hispano-marroquí (Madrid, 28-29 de abril de 1999). Ibid, pp. $288-294$.

27 Declaración conjunta VI Reunión de Alto Nivel hispano-marroquí (Marrakech, 8-9 de diciembre de 2003). Ibid, pp. 294-303.
} 
que llama la atención al leer la declaración final de la reunión es la mención a la decisión de lanzar un Programa de Enseñanza de Lengua Árabe y Cultura Marroquí para el alumnado marroquí escolarizado en España, cuando ese Programa ya venía funcionando desde el curso 1994-1995 y había contado en el curso anterior a la celebración de la Reunión de Alto Nivel con la participación de 1286 alumnos y 23 profesores repartidos en 53 centros educativos (Mijares, 2006a: 36).

En la VII RAN de 2005 celebrada entre Córdoba y Sevilla, ambos Gobiernos expresaron de nuevo su intención de intensificar y profundizar en la colaboración y cooperación en el ámbito educativo en el marco de la Charte Nationale d'Éducation et de Formation que había sido aprobada por Marruecos en 1999 con el objetivo de luchar contra el analfabetismo, mejorar la calidad de la educación y luchar contra las desigualdades (Meziane, 2000: 80). En esta reunión se mostró, por una parte, el interés por propiciar y favorecer el intercambio de expertos en Educación así como la información y los encuentros entre las autoridades y entidades educativas de ambos países. Por otra parte, ambas partes coincidieron en su interés para acelerar la construcción y puesta en funcionamiento de un segundo centro educativo español en Rabat -Instituto Español de Educación Secundaria-. En la reunión se manifestó igualmente el interés por la ampliación de la enseñanza de la Lengua Española en el sistema educativo reglado marroquí y se acordó establecer un Plan de Actuación conjunto para establecer de forma específica las medidas a aplicar de forma progresiva en los siguientes cinco años ${ }^{28}$.

La cooperación educativa también formó parte de la agenda de la VIII RAN celebrada en Rabat en 2007 en la que los dos países mostraron su interés por extender el Programa de Enseñanza de LACM en España. De los 83.379 alumnos marroquíes matriculados en el curso 2005-2006 en el sistema educativo español sólo 3.469 se habían beneficiado del Programa. Como resultado tangible de la reunión fue firmado un Acuerdo en virtud del cual el Gobierno marroquí puso a disposición de España un terreno para la construcción de un nuevo edificio del Colegio español de Rabat ${ }^{29}$.

En la IX RAN celebrada en 2008 se acordó la puesta en marcha de un proyecto de colaboración para impulsar la enseñanza del español en Marruecos como lengua extranjera. También se decidió la puesta en marcha de un sistema de evaluación del LACM que permitiera monitorizar el desarrollo del Programa en los centros en los que estaba implantado, establecer foros de intercambio vía internet así como apoyar la publicación de una guía pedagógica para los docentes, ${ }^{30}$ que fue publicada en 2009 como veremos más adelante.

Hubo que esperar cuatro años para que en 2012 tuviera lugar la X RAN. La Declaración Final subrayaba el éxito de los programas de enseñanza del árabe y el español en los respectivos sistemas educativos. Ambas partes también mostraron su satisfacción por la promoción de la enseñanza del español en los centros escolares y de formación profesional españoles en Marruecos y en la red de los Institutos Cervantes. También fue respaldada la decisión del Gobierno de Marruecos por la que la lengua española fuera ofrecida como asignatura optativa al alumnado de los centros de enseñanza primaria y secundaria en Marruecos. Con este propósito, los dos Gobiernos decidieron emprender conjuntamente la realización de un estudio sobre el uso de la lengua española en Marruecos, que abordara su potencial como motor de actividades productivas (Torrejón y Zebda, 2013). En el marco de esta Reunión fue firmado un Acuerdo de Asociación Estratégica en materia de desarrollo y de cooperación cultural, educativa y deportiva entre el Reino de Marruecos y el Reino de España que actualizaba el Convenio Cultural bilateral firmado en 1980.

\footnotetext{
${ }^{28}$ Declaración conjunta. VII Reunión de Alto Nivel entre los Reinos de España y Marruecos (Córdoba-Sevilla, 29 de septiembre de 2005). Ibid, pp. 303-318.

${ }^{29}$ Declaración conjunta. VIII Reunión de Alto Nivel entre los Reinos de España y Marruecos (Rabat, 5-6 de marzo de 2007). Ibid, pp. 318-329.

${ }^{30}$ Declaración conjunta «Socios para el desarrollo». IX Reunión de Alto Nivel entre España y Marruecos, Madrid, 16 de diciembre de 2008. ). Ibid, pp. 329-343.
} 
En la XI RAN celebrada en 2015 se expresó la satisfacción por los avances realizados en la aplicación del Programa LACM en España. En esa reunión, el Gobierno de España se comprometió a introducir la enseñanza de la lengua árabe y de la historia y la geografía marroquí en la red de los centros escolares españoles en Marruecos. Asimismo, ambos países convinieron en fomentar la enseñanza del idioma español en los centros escolares de Marruecos. En este sentido, el Gobierno español mostró su voluntad de colaborar en la puesta en marcha del proyecto de bachillerato marroquí internacional opción "español" implantado por el Ministerio de Educación Nacional y de la Formación Profesional durante el curso 2014-2015 en un centro de la región Tetuán-TángerAlhucemas y en otro de la región Oriental. Esta modalidad, al igual que la de "ingles", tenía carácter de experiencia piloto a diferencia de la opción "francés" que ya estaba implantada como mínimo en un centro de cada región. Esta mayor preocupación lingüística se enmarcaba en lo previsto en el artículo 5 de la Constitución marroquí de 2011:

“procurará (el Estado) lograr la coherencia de la política nacional, lingüística, así como fomentar el aprendizaje y dominio de los idiomas extranjeros más utilizados en el mundo, en atención a su naturaleza de medios de comunicación y asociación y de interacción con la sociedad del conocimiento y de apertura a las diversas culturas y a la civilización moderna» (Daranas, 2011).

\section{Los programas de enseñanza de la lengua y cultura de origente en Europa y España}

Tras la Segunda Guerra Mundial, la necesidad de disponer de mano de obra con la que afrontar los procesos de reconstrucción y desarrollo convirtió a los países de Europa Occidental en receptores de inmigrantes. Para ello fueron firmados acuerdos con los países de origen que facilitaron la llegada de trabajadores temporales con la condición de que posteriormente retornaran a su país de origen. Bajo estas condiciones los trabajadores extranjeros quedaban excluidos de la sociedad, vivían en barracones creados precisamente para ellos y que eran desmantelados una vez acabadas las estancias de trabajo (Mijares, 2006a: 35).

La crisis económica de los años setenta en Europa obligó a frenar este tipo de inmigración y estuvo acompañada de la puesta en marcha de políticas de retorno. Hasta ese momento se pensaba en la inmigración como algo temporal. Esta idea fue la que impulsó la implantación de los programas de lengua y cultura de origen (ELCO) destinados a capacitar a los hijos de los inmigrantes para su retorno, contribuyendo a mantener los vínculos identitarios con la sociedad de sus padres (Mijares, Martín, 2007:103). Los Gobiernos europeos colaboraban con los de los países de origen en la preparación del retorno de los trabajadores y de sus hijos. A través de convenios bilaterales, los Gobiernos de origen se encargaban de gestionar los programas ELCO asumiendo la selección, formación y remuneración de los profesores así como la elaboración del material de enseñanza utilizado en las clases del programa.

Este tipo de cooperación está recogida en el artículo 15 del Convenio Europeo relativo al Estatuto Jurídico del Trabajador Migrante de 1977:

"Las Partes Contratantes interesadas tomarán medidas de común acuerdo con vistas a organizar, en lo posible, cursos especiales para los hijos de los trabajadores migrantes, 
destinados a enseñarles la lengua materna del trabajador migrante y a facilitar, entre otras cosas, su retorno a su Estado de origen"31.

La constatación de que los inmigrantes no regresaban a sus países de origen y el aumento del número de inmigrantes como consecuencia de los procesos de reagrupación familiar (Mijares, 2006:39), obligó a los Estados europeos a cambiar sus planteamientos respecto a la inmigración estableciendo políticas de integración en las que se reconocían sus derechos como trabajadores extranjeros incluyendo la escolarización de sus hijos (Mijares, 2005a: 338). Los programas de enseñanza de la lengua y cultura de origen fueron mantenidos al ser considerados un instrumento con el que alcanzar una educación equilibrada limitando el fracaso escolar.

Estas cuestiones fueron reforzadas en el marco de la Comunidad Europea a través de la Directiva Comunitaria 486/1977 que establecía en su artículo 3ㅇ:

"De conformidad con sus situaciones nacionales y sistemas jurídicos, y en cooperación con los Estados de origen, los Estados miembros adoptarán las medidas pertinentes con miras a promover, en coordinación con la enseñanza normal, una enseñanza de la lengua materna y de la cultura del país de origen" ${ }^{\prime 32}$.

Aunque la Directiva señalaba la obligación de los Estados miembros para promover la enseñanza de la lengua materna y de la cultura de los países de origen dejaba un alto grado de flexibilidad en cuanto a las formas de hacerlo ${ }^{33}$. Países como España, Francia o Bélgica, entre otros, firmaron acuerdos bilaterales con los países de origen. En los Países Bajos estos programas de formación fueron financiados directamente por el sistema educativo nacional.

Otras resoluciones, informes y recomendaciones de las instituciones europeas coinciden en considerar la enseñanza de la lengua materna a los hijos de inmigrantes como una necesidad con la que preservar su patrimonio cultural, facilitar el aprendizaje de la lengua de acogida y contribuir a la construcción de una identidad equilibrada. La ruptura lingüística entre el entorno familiar y el entorno escolar es considerada como un factor que tiende a favorecer el fracaso escolar y el aislamiento de las familias respecto a la comunidad. Por ello el Parlamento Europeo considera indispensable la integración lingüística desde la edad preescolar fomentando medidas que permitan a los hijos de inmigrantes profundizar en el conocimiento de su lengua materna ${ }^{34}$. Esta Resolución del Parlamento Europeo considera que:

"los hijos de inmigrantes en edad escolar tienen derecho a una enseñanza pública, cualquiera que sea el estatuto jurídico de su familia, y que este derecho incluye el aprendizaje de la lengua del país de acogida, sin perjuicio del derecho de estos niños al aprendizaje de su lengua materna"

La Resolución igualmente considera que:

\footnotetext{
${ }^{31}$ Convenio Europeo relativo al Estatuto Jurídico del Trabajador Migrante, hecho en Estrasburgo el 24 de noviembre de 1977, BOE, no 145, de 18 de junio de 1983. https://www.boe.es/diario boe/txt.php?id=BOE-A-1983-17038 [consulta: 11 de abril de 2021].

32 Unión Europea. Directiva (UE) 77/486/CEE del Consejo, de 25 de julio de 1977, relativa a la escolarización de los hijos de los trabajadores migrantes. DOUE L 199, 06 de agosto de 1977, pp 32-33. https://eur-lex.europa.eu/legalcontent/ES/TXT/?uri=celex\%3A31977L0486 [consulta: 11 de abril de 2021].

${ }^{33}$ Ver igualmente el Libro Verde de la Comisión Europea, de 3 de julio de 2008, titulado «Inmigración y movilidad: retos y oportunidades de los sistemas educativos de la UE". COM (2008) 423 final.

https://eur-lex.europa.eu/LexUriServ/LexUriServ.do?uri=COM:2008:0423:FIN:ES:PDF [consulta: 10 de abril de 2021].

${ }^{34}$ Unión Europea, Resolución del Parlamento Europeo 2004/2267(INI) sobre la integración de los inmigrantes mediante una escuela y una enseñanza multilingües. DOUE C 233 E, 28 de septiembre de 2006, pp. 121-124.
} 
"incluso cuando los hijos y/o descendientes de los inmigrantes (de segunda y tercera generación) dominan la lengua del país de acogida, es oportuno permitir que estos niños puedan tener acceso a su lengua materna y a la cultura de su país de origen".

El Libro Verde de la Comisión Europea sobre «Inmigración y movilidad: retos y oportunidades de los sistemas educativos de la UE" publicado en 2008 insiste en que las aulas y los colegios tienen que incorporar una mayor diversidad de lenguas maternas, perspectivas culturales y conocimientos. Incide asimismo en la importancia de desarrollar nuevas capacidades docentes y nuevas formas de estrechar los lazos con las familias y las comunidades inmigrantes ${ }^{35}$.

La Resolución del Parlamento Europeo de 2 de abril de 2009 sobre la educación de los hijos de los inmigrantes ${ }^{36}$ también considera que conservar y fomentar el multilingüismo debe formar parte obligada de todos los programas escolares insistiendo en que el aprendizaje de idiomas desde la etapa preescolar debería ser promovido con el fin de favorecer la inclusión de la población inmigrante. Asimismo considera que la integración de la lengua materna en los planes de estudio debe ser una tarea confiada expresamente a los Estados miembros con el fin de preservar su patrimonio cultural. Esta Resolución

"destaca la importancia de desarrollar las competencias en comunicación intercultural de los niños, tanto de la población inmigrante como de los países de acogida, y considera que la capacidad de comunicar la cultura propia y de comprender la cultura y los valores de los demás constituye un elemento central de la competencia clave «conciencia y expresión culturales»" ${ }^{37}$.

En la actualidad la enseñanza de la Lengua Árabe y Cultura Marroquí forma parte de la enseñanza pública nacional a través de acuerdos bilaterales firmados por Marruecos con Alemania, Bélgica, España y Francia. Las clases suelen impartirse en horario no escolar, a excepción de España en donde existe una modalidad de enseñanza de la LACM en horario lectivo, como veremos más adelante.

Como se puede observar en la figura 1, Francia es el país en el que más implantado está el Programa de Enseñanza de la Lengua Árabe y Cultura Marroquí. De acuerdo con los datos facilitados por la Fundación Hassan II de Marroquíes Residentes en el Extranjero encargada de la gestión del programa y de la elección de los profesores, el 66,55\% de los alumnos que lo siguen lo hacen en centros educativos franceses. A mucha distancia, España ocupa el segundo lugar tanto en número de alumnos, como de centros y profesores.

\footnotetext{
${ }^{35}$ Libro Verde de la Comisión Europea, de 3 de julio de 2008, titulado «Inmigración y movilidad: retos y oportunidades de los sistemas educativos de la UE. COM (2008) 423 final. https://eurlex.europa.eu/LexUriServ/LexUriServ.do?uri=COM:2008:0423:FIN:ES:PDF [consulta: 11 de abril de 2021]. [consulta: 11 de abril de 2021].

${ }^{36}$ Resolución del Parlamento Europeo, (2008/2328(INI), de 2 de abril de 2009, sobre la educación de los hijos de los inmigrantes. DOUE C 137 E, 27 de mayo de 2010, pp. 1-5. https://eur-lex.europa.eu/legalcontent/ES/TXT/?uri=OJ:C:2010:137E:TOC [consulta: 11 de abril de 2021].

${ }^{37}$ Ibid., Resolución del Parlamento Europeo, de 2 de abril de 2009, p. 3.
} 
Fig. 1: PROGRAMA LACM CURSO 2016-2017 en Europa

\begin{tabular}{|l|l|l|l|l|l|l|}
\hline País & $\begin{array}{l}\text { Número } \\
\text { de } \\
\text { centros }\end{array}$ & $\begin{array}{l}\text { Porcentaje } \\
\%\end{array}$ & $\begin{array}{l}\text { Número de } \\
\text { profesores }\end{array}$ & $\begin{array}{l}\text { Porcentaje } \\
\%\end{array}$ & $\begin{array}{l}\text { Número de } \\
\text { alumnos }\end{array}$ & $\begin{array}{l}\text { Porcentaje } \\
\%\end{array}$ \\
\hline Francia & 1773 & 72,24 & 365 & 70,87 & 33.217 & 66,55 \\
\hline España & 533 & 21,71 & 96 & 18,64 & 9223 & 18,48 \\
\hline Bélgica & 108 & 4,42 & 45 & 8,74 & 5869 & 11,75 \\
\hline Alemania & 40 & 1,63 & 9 & 1,75 & 1609 & 3,22 \\
\hline Total & 2454 & 100 & 515 & 100 & 49.918 & 100 \\
\hline
\end{tabular}

Fuente: Elaboración propia a partir de datos facilitados por la Fundación Hassan II de Marroquíes Residentes en el Extranjero.

Otros países europeos disponen de programas similares sin que estos sean el resultado de acuerdos bilaterales firmados con Marruecos. Es el caso de los Países Bajos donde el programa recibe el nombre de Onderwijs in Allochtone Levende Talen (OALT). El Ministerio de Educación holandés se encarga de reclutar directamente al profesorado sin la participación de las autoridades marroquíes, de organizar su formación y de elaborar los materiales didácticos (Richters, 1999: 106). La formación en lenguas vivas alóctonas es considerada por el Gobierno holandés como una herramienta para la construcción identitaria del alumnado extranjero que le ayuda a reforzar la adquisición del neerlandés.

\section{La implantación del Programa de Enseñanza de la Lengua Árabe y Cultura Marroquí (LACM) en España}

De acuerdo con la Directiva Comunitaria 486/1977 que deja a los Estados miembros flexibilidad para establecer las medidas necesarias para la enseñanza de las lenguas de origen de las comunidades inmigrantes, España ha optado por la firma de acuerdos bilaterales para su implantación. En la actualidad tiene dos acuerdos firmados con dos países vecinos, uno con un país comunitario Portugal- y otro con un país extracomunitario: Marruecos. Este último fue firmado en 1980 y entró en vigor en 1985 pero su implantación se retrasó hasta el Curso 1994-1995.

La implantación del Programa LACM se vio impulsada por el crecimiento del alumnado de origen marroquí en los colegios españoles. Su número se ha incrementado debido, en primer lugar, a las reagrupaciones familiares ${ }^{38}$, y en segundo lugar, al nacimiento de niños de padres marroquíes en España. En el curso 1994-1995 había 8576 alumnos marroquíes matriculados lo que suponía el 16\% de los estudiantes extranjeros matriculados aquel año escolar. Según las estadísticas publicadas en la página web del Ministerio de Educación, Cultura y Deporte, de los 795.525 de los alumnos

\footnotetext{
${ }^{38}$ Artículo 53.c de Real Decreto 557/2011, de 20 de abril, por el que se aprueba el Reglamento de la Ley Orgánica 4/2000, sobre derechos y libertades de los extranjeros en España y su integración social, tras su reforma por Ley Orgánica 2/2009 “El extranjero podrá reagrupar con él en España a los siguientes familiares:... Sus hijos o los de su cónyuge o pareja, incluidos los adoptados, siempre que sean menores de dieciocho años en el momento de la solicitud de la autorización de residencia a su favor o tengan una discapacidad y no sean objetivamente capaces de proveer a sus propias necesidades debido a su estado de salud". https://www.boe.es/buscar/act.php?id=BOE-A-2011-7703 [consulta: 11 de abril de 2021].
} 
extranjeros matriculados en el curso 2018-2019 en colegios españoles, $191.256^{39}$ eran marroquíes lo que significaba más del $24 \%$ del total de alumnado extranjero. Hay que subrayar que estas cifras no incluyen a los alumnos de nacionalidad española con origen marroquí.

Como hemos mencionado anteriormente fue el Convenio de Cooperación Cultural de 1980 el que estableció las bases sobre las que sustenta el Programa de Enseñanza de la Lengua Árabe y la Cultura Marroquí (LACM). En el artículo IV.2 establecía que:

“El Gobierno español facilitará la enseñanza de la Lengua Árabe a los alumnos marroquíes escolarizados en establecimientos primarios y secundarios españoles.

A este efecto, las autoridades españolas competentes pondrán a disposición de los profesores marroquíes encargados de esta enseñanza las aulas necesarias, de estos profesores se hará cargo íntegramente Marruecos".

A través de este Programa se enseña la lengua árabe y la cultura marroquí al alumnado marroquí escolarizado en los centros educativos españoles. Igualmente se oferta al alumnado no marroquí que pudiera estar interesado.

Los objetivos del programa son, en primer lugar, proporcionar a los alumnos marroquíes una formación que les ayude a salvaguardar su identidad; en segundo lugar, vivir su cultura respetando la del país de acogida, tener confianza en ellos mismos y en su porvenir dejando a un lado los aspectos negativos que puedan generar los efectos de la inmigración; en tercer lugar, apoyar la integración escolar y sociocultural de estos alumnos en el sistema educativo español y en la sociedad española; en cuarto lugar, conseguir su adaptación en la escuela y en su nueva vida (para los recién llegados) desarrollando para ello valores de tolerancia y solidaridad; y finalmente, fomentar la educación intercultural, tratando de superar el tradicional modelo ELCO (Embajada del Reino de Marruecos en Madrid, 2009).

Durante la tercera reunión de la Comisión Mixta Hispano-Marroquí de Cooperación Cultural y Educativa ${ }^{40}$ celebrada en Rabat en 1992 se acordó la creación de un grupo mixto encargado de "estudiar las modalidades de aplicación de dicho proyecto" (Mijares, 2005:116). El Grupo Mixto de Expertos Hispano-Marroquí fue creado en 1994 y estuvo formado por responsables educativos españoles y marroquíes. Las líneas del Programa LACM fueron establecidas tras la celebración de dos reuniones. La primera tuvo lugar en Rabat en abril de 1994 y la segunda en Ávila en julio de ese mismo año (Nechda 1999: 180). El Programa comenzó a implementarse durante el curso 1994-1995, aunque en los dos cursos anteriores se habían comenzado a impartir clases experimentales en algunos centros como el colegio Antonio Moreno Rosales de la Comunidad de Madrid (García, 1999: 166).

39 http://estadisticas.mecd.gob.es/EducaJaxiPx/Datos.htm?path=/Educacion/Alumnado/Matriculado/20182019RD/Extranjeros//I0/\&file=Extran3.px\&type=pcaxis [consulta: 11 de abril de 2021].

${ }^{40}$ La Comisión fue creada por el artículo XXXVI del Convenio de Cooperación Cultural entre España y Marruecos de 1980 “para vigilar la aplicación del presente convenio será constituida una comisión mixta permanente. Quedará compuesta por un número igual de miembros designados por cada uno de los dos gobiernos, y a ella podrán sumarse los expertos que se estimen necesarios. la comisión mixta se reunirá cada vez que lo desee uno de los dos gobiernos y al menos una vez cada dos años, alternativamente, en uno u otro país. La presidencia de las reuniones corresponderá a uno de los representantes del estado en el cual tengan lugar y, lo que sea decidido en las reuniones y consignado en el acta final, tendrá carácter obligatorio para los dos países". 
La implantación del Programa coincidió con la entrada en vigor en 1993 del Tratado de Amistad, de Buena Vecindad y de Cooperación entre España y Marruecos en el que se reiteraba la voluntad de llevar a cabo esta iniciativa en su artículo 9:

"Las dos Partes acuerdan brindar una particular atención a la enseñanza del idioma y de la civilización árabes en España y de la lengua y de la civilización españolas en Marruecos, así como a la instalación y funcionamiento de Centros Culturales en sus respectivos territorios."

La importancia atribuida a las lenguas de origen quedó también recogida en el Plan Estratégico Ciudadanía e Integración de $2011-2014^{41}$ en el que se insistía en la necesidad de fomentar acciones relacionadas con las lenguas y culturas de origen del alumnado inmigrante dirigidas al alumnado o a la comunidad educativa en su conjunto así como el impulso al reconocimiento curricular del conocimiento de lenguas vehiculares de los países de origen del alumnado extranjero. Hay que subrayar que no hubo una versión posterior del último Plan Estratégico de Ciudadanía e Integración de 2011-2014.

El aumento del número de alumnos marroquíes que lo cursaban y la ampliación de los centros que lo impartían hizo necesario fijar las orientaciones del Programa. El Grupo Mixto de Expertos Hispano-Marroquí acordó en su VIII reunión de 2007 actualizar la Guía Práctica de Profesorado de Lengua Árabe y Cultura Marroquí. Para ello fue creado un grupo de trabajo integrado por profesores de centros educativos españoles en los que se impartía el Programa LACM y por representantes de la Misión Cultural Marroquí en Madrid, coordinada por la Embajada de Marruecos en Madrid bajo la dirección del Centro de Investigación y Documentación Educativa (CIDE) del Ministerio de Educación español.

La Guía Práctica del profesorado de la Lengua árabe y Cultura Marroqui ${ }^{42}$ fue aprobada en la IX Reunión del Grupo Mixto de Expertos celebrada en Rabat en junio de 2008 y fue publicada en el 2009 en castellano y árabe. La Guía tuvo como objetivo adaptar su contenido a los cambios introducidos en los dos sistemas educativos, tanto en la Charte Nationale d'Éducation et de Formation ${ }^{43}$ creada por Marruecos en 1999 como en la Ley Orgánica de Educación (LOE) aprobada en 2006 por España ${ }^{44}$.

El Programa de Lengua Árabe y Cultura Marroquí se imparte en dos modalidades diferentes. En la Modalidad A o no integrada, diseñada para los centros escolares con un número reducido de alumnos marroquíes, las clases se imparten fuera del horario lectivo y un mismo profesor marroquí atiende a varios centros educativos. En la Modalidad B o integrada, diseñada para los centros con un número elevado de alumnos marroquíes, las clases se imparten en horario lectivo y el profesor marroquí realiza su labor en exlusiva en el centro al que está asignado. El profesorado es seleccionado por Marruecos a través de la Fundación Hassan II de Marroquíes Residentes en el Extranjero ${ }^{45}$ teniendo que cumplir como requisitos con un mínimo de 4 años de experiencia docente en Marruecos, el conocimiento del español y estar en posesión de una licenciatura.

\section{Análisis y valoración del Programa LACM}

\footnotetext{
41 http://www.nadiesinfuturo.org/IMG/pdf/PLAN ESTRATEGICO CIUDADANIA E INTEGRACION 2011-2014.pdf [consulta: 11 de abril de 2021].

42 https://sede.educacion.gob.es/publiventa/guia-practica-del-profesorado-de-lengua-arabe-y-culturamarroqui/lengua-arabe-cultura-marruecos/12638 [consulta: 11 de abril de 2021].

${ }^{43}$ https://www.men.gov.ma/Fr/Pages/CNEF.aspx [consulta: 11 de abril de 2021].

44 Después de 2009 no se ha hecho ninguna actualización de la Guía a pesar de la promulgación en 2013 de la nueva Ley de Educación, Ley Orgánica 8/2013, de 9 de diciembre, para la mejora de la calidad educativa (LOMCE), BOE, no 295, 10 de diciembre de 2013. https://www.boe.es/diario boe/txt.php?id=BOE-A-2013-12886 [consulta: 11 de abril de 2021].

45 https://www.fh2mre.ma/lenseignement-de-la-langue-arabe-et-de-la-culture-marocaine-elacm/ [consulta: 11 de abril de 2021].
} 
La implantación del Programa LACM se ha enfrentado a importantes limitaciones resumidas en la Guía Práctica del profesorado de la Lengua árabe y Cultura Marroquí:

"Las propias limitaciones del horario y la propia naturaleza del Programa de Enseñanza de Lengua Árabe y Cultura Marroquí, así como la complejidad de la organización de la programación de las enseñanzas regladas del currículo y de las actividades complementarias de los centros educativos, dificultan alcanzar en su totalidad los objetivos y desarrollar todos los contenidos diseñados. Estas limitaciones deben llevar al profesorado a cuidar la programación de aula, intentando alcanzar el mayor grado de desarrollo de los contenidos tanto lingüísticos como culturales e interculturales" (González Briones, 2009).

Estas dificultades se ven agravadas por la escasez de materiales pedagógicos a disposición del profesorado. Hasta 2009 la única obra disponible era Ensemble pédagogique pour l'enseignement de la langue arabe et de la culture marocaine aux enfants marocains résidents à l'étranger. Objectifs et orientations pédagogiques elaborada por el Ministerio de Educación Nacional de Marruecos en 1994 y traducida al español en 2003. Con la intención de suplir esa carencia fue elaborada la Guía Práctica del Profesorado de Lengua Árabe y Cultura Marroquí con el objetivo de "volver a definir los objetivos y contenidos y renovar la metodología, para asegurar el progreso en el aprendizaje significativo que solucione los problemas percibidos actualmente por los profesores que trabajan en el Programa".

A la dificultad que supone la ausencia de materiales docentes se añade el desconocimiento que muchos profesores del programa tienen de la cultura española. En palabras de Moscoso "no sabemos hasta qué punto se tiene en cuenta las especificidades del niño de origen marroquí que está creciendo en nuestro país y se educa en el sistema español" (Moscoso 2013: 125).

Por otra parte, el hecho de que el Programa LACM se imparta en horario extraescolar en la Modalidad $A$ y que sus contenidos no formen parte del curriculum docente acentúa el aislamiento de los profesores marroquíes respecto al resto del claustro (Arias, 1999: 203).

Otra de las deficiencias de este Programa es su organización debido a la disparidad de niveles de conocimiento de la lengua árabe que tienen los estudiantes. En la Modalidad B, las clases se imparten en el mismo horario lectivo de las clases de religión católica lo que hace que en una misma clase haya alumnos de la misma edad, pero con conocimientos distintos del árabe. (Mijares, 2005: 118). La existencia de niveles distintos dificulta la tarea del profesor, situación que se ve complicada por la limitación de materiales docentes mencionada anteriormente.

Otra de las razones que explicarían el fracaso de este Programa es el idioma utilizado en las clases al ser impartidas en árabe clásico o literal y no en el árabe marroquí o dialectal o en amazigh. Hay que tener en cuenta, que el árabe clásico en Marruecos no es la lengua materna ni el idioma que se utiliza en el entorno familiar o social. El árabe clásico es una lengua académica que se aprende una vez que el alumno empieza el colegio. Por esta razón hay voces que reivindican la introducción en el Programa del árabe dialectal marroquí o del amazigh en su condición de lenguas maternas. Moscoso, por ejemplo, considera que hay que aprovechar la "educación en la diversidad" prevista en la LOGSE para proponer que sea incluida la lengua nativa de los ciudadanos de origen marroqui" (Moscoso, 2013: 134). Mijares, por su parte, considera que la enseñanza en árabe clásico no contribuye a alcanzar los objetivos de un correcto desarrollo cognitivo del alumno y su integración en el sistema educativo español (2006: 345). Moscoso junto a otros, propone que la primera lengua de enseñanza en el marco de la LACM sean el árabe marroquí o el amazigh (L1) y que el árabe clásico 
y el español sean consideradas como L2 (Moscoso, 2013: 135). Para este autor valorar la lengua nativa significaría terminar con una situación de opresión que el poder educativo monolingüe mantiene como garante de sus intereses frente a los grupos más desprotegidos (Moscoso, 2013: 135). Su utilización sería la única manera para que los niños puedan alcanzar un desarrollo cognitivo óptimo en su primera lengua lo que les ayudará a la hora de adquirir su segunda lengua que es el español o el árabe clásico (Baker, 1997: 193).

Estas carencias se encuentran en el origen del escaso interés que el Programa suscita entre el alumnado marroquí. Aunque el número de centros, profesores y alumnos ha aumentado como se puede observar en los siguientes gráficos, la cifra global de estudiantes sólo representa el $8 \%$ del alumnado marroquí matriculado en los centros públicos españoles.

Fig. 2: Centros donde se imparte LACM en España

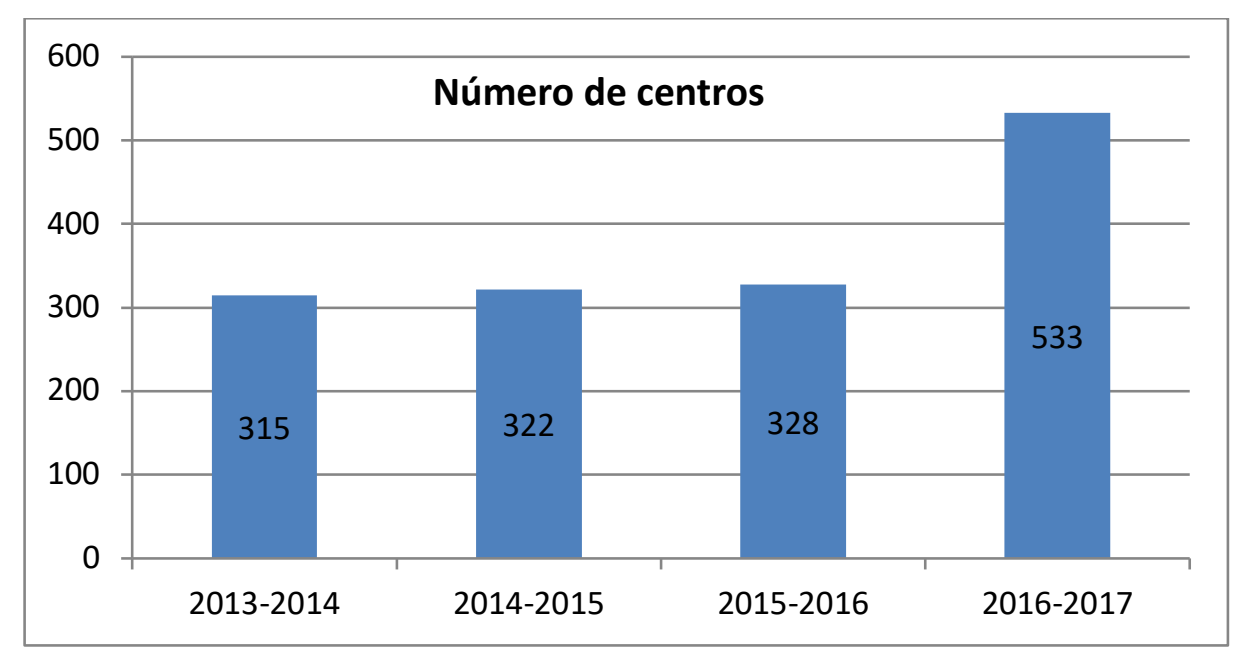

Fuente: Elaboración propia a partir de datos facilitados por la Fundación Hassan II de Marroquíes Residentes en el Extranjero.

Fig. 3: Alumnado marroquí matriculado en centros públicos españoles y alumnado matriculado en LACM

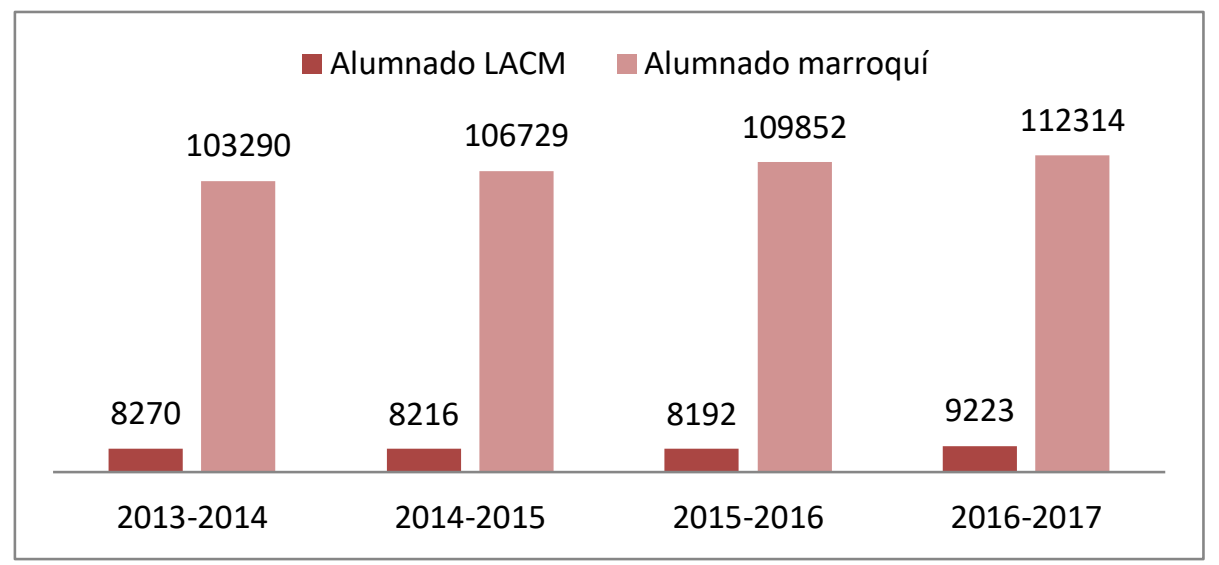

Fuente: Elaboración propia a partir de Datos facilitados por la Fundación Hassan II de Marroquíes Residentes en el Extranjero (alumnado LACM), Estadísticas del Ministerio de Educación (alumnado marroquí matriculado en centros educativos españoles de primaria, ESO y bachillerato). 
Los alumnos nacidos en España que hablan español perfectamente y que en sus casas se comunican con sus padres y familiares en dialecto marroquí o amazigh consideran el árabe clásico como una lengua desconocida que aunque pertenece a su legado cultural no usan, dominan ni entienden. Este perfil de alumnos no ve el interés por aprender un idioma extraño para ellos, aunque algunos acuden a las clases de LACM obligados por sus padres (Arias, 1999: 207). Por su parte, los alumnos marroquíes que se incorporan al sistema educativo después de haber estado escolarizados en Marruecos tienen un problema más grave, la falta del dominio del idioma español lo que conduce al rechazo y a la exclusión social. Esta cuestión afecta la construcción de la identidad del niño, ya que aprender una lengua, conduce a conocer los valores culturales de la nueva sociedad lo que, a su vez, ayuda al reconocimiento y la valorización de la suya. Por lo tanto, su preocupación y la de sus padres es adaptarse a su nueva realidad y aprender el español. Algunos de estos estudiantes participan en el programa LACM pero cuando ya disponen de un nivel de español más avanzado.

La calidad del LACM se resiente también por la ausencia de mecanismos de evaluación del Programa como del ejercicio docente del profesorado que participa en el mismo, tanto global de la iniciativa así como desde los profesores que en muchas ocasiones se empeñan en impartir sus clases y se descuidan de hacer un seguimiento de los conocimientos lingüísticos de sus alumnos (Arias, 1999: 207).

\section{El español en la educación no universitaria en Marruecos}

La enseñanza oficial del español en Marruecos tiene lugar a través de dos vías: la posibilidad de cursarlo en el sistema educativo marroquí tanto en secundaria como en bachillerato y a través de la red de colegios españoles que el Ministerio de Educación de España tiene en el país. Antes de ver cómo se plantean estas dos formas de enseñanza del español, es necesario hacer un recorrido histórico para entender la situación del español en la enseñanza en Marruecos.

La independencia de Marruecos en 1956 estuvo acompañada del abandono de la enseñanza del español tal y como se había realizado durante el Protectorado español (González González 2011). Varios factores explican este retroceso. Por un lado el impulso a la arabización y por otro el fomento de la lengua francesa apoyado por las élites marroquíes que habían estudiado en los colegios franceses. El francés se convirtió en la lengua extranjera utilizada en la administración de la antigua zona de influencia española. Su conocimiento se transformó en un instrumento de movilidad social en un contexto en el que España parecía "perder todo interés por la continuidad y la suerte de su legado cultural en Marruecos a partir de su salida" (Roldan, 2006: 26).

El Convenio Cultural Hispano-marroquí firmado en 1957 establecía en su artículo 3 el compromiso de ambos países para fomentar el estudio de la lengua y de la cultura española. El alcance de esta declaración se veía limitado por la disposición, recogida en el Protocolo Anejo, por el que las autoridades españolas deberían transferir los colegios españoles que habían funcionado durante el Protectorado a la administración marroquí durante los dos cursos siguientes. El Convenio dejaba abierta la posibilidad de que el Gobierno español pudiera crear ex novo centros educativos tanto públicos como privados en el país.

En esas circunstancias hubo un rechazo al aprendizaje del idioma español, ejemplo de ello es que en 1978 el Gobierno incitó a los alumnos a escoger el español como opción más entre el inglés o el alemán, pero hubo un desinterés en optar por el español (Benyaya, 2007: 171). En los años setenta los manuales de enseñanza del español eran editados por autores franceses y transmitían imágenes estereotipadas sobre el español. 
Según Fernández Suzor (1993), España había perdido durante 23 años-hasta la firma del siguiente convenio de 1980- una oportunidad para ser el país donde se hubiera formado un importante número de cuadros y licenciados marroquíes, que hubiera podido contribuir a crear una élite hispanófona capaz de defender los intereses españoles.

En los años ochenta se percibe el interés por parte de España de fomentar su cultura en Marruecos. Esto se plasmó a través del Convenio de Cooperación Cultural firmado en 1980 como hemos visto en el apartado II.1 de este trabajo.

Antes de los noventa el español sobrevivía de una manera inconexa y aislada, "Marruecos tuvo mucha voluntad y poca ayuda de España para el mantenimiento del español en su sistema educativo" (Amirah, 2015: 103).

A partir de los años 90, hubo una importante transformación con la creación de la Consejería de Educación en la Embajada Española en Marruecos en 1989, la creación en 1991 de una Comisión Interministerial "ex profeso" entre el Ministerio de Asuntos Exteriores, el de Educación y de Cultura para replantear la estrategia de la acción cultural española en Marruecos, y la creación del Instituto Cervantes y la firma del Acuerdo de Amistad, Buena vecindad y Cooperación en 1991.

La Consejería dio un impulso al español en Marruecos ya que su objetivo era la reorganización y modernización de la red educativa, además de "culminar y concretar todo este proceso de acercamiento y de cambio de signo en la política educativa y cultural española, después de tantos años de desencuentro" (Roldan 2006: 33).

En 1990 surge la primera colaboración con el Ministerio de Educación marroquí, a través de la creación del "Equipo de Apoyo" integrado por un grupo de profesores de español. Esta estructura dio origen a la llamada Asesoría Técnica Lingüística compuesta por 6 asesores que con el paso del tiempo pasaron a ser 20 (Roldan, 2006: 33). Actualmente, cuenta con seis asesorías técnicas situadas en diferentes ciudades marroquíes: Agadir, Casablanca, Fez, Rabat, Tánger y Tetuán.

“Las Asesorías Técnicas están encargadas de desarrollar los programas de Cooperación, en materia educativa, se llevan a cabo anualmente entre la Consejería de Educación y el Ministerio de Educación Nacional marroquí. Son programas orientados, fundamentalmente, a la promoción y difusión de la Lengua y Cultura Españolas en la Educación Secundaria en Marruecos" (Revilla, Vílchez, 2006:50).

En palabras de la Consejera de Educación Magdalena Roldán (2006):

"Las acciones desarrolladas por la Consejería, desde su creación hasta la actualidad, han ido propiciando lentamente una evolución en la didáctica del español, gracias a un mayor y mejor conocimiento de los nuevos enfoques metodológicos y a los nuevos materiales que los profesores e inspectores marroquíes han empezado a manejar, lo que se ha plasmado en las diferentes versiones de las nuevas Orientaciones Pedagógicas elaboradas".

Por lo tanto, como veremos más adelante, la Consejería de Educación, no solo consiguió reorganizar la enseñanza del español en los centros donde se impartía, sino que ha introducido el español en la secundaria del sistema educativo marroquí.

Actualmente, la Consejería de Educación tiene dos acciones; una directa a través de los Centros Educativos españoles, y otra indirecta, a través de los programas de cooperación con el Ministerio de Educación Nacional marroquí.

La enseñanza del español como lengua extranjera en el sistema educativo marroquí

Marruecos es un país plurilingüe en el que el árabe clásico, el árabe dialectal -con sus variedades dependiendo de cada zona-, el amazigh, el francés, el español y el inglés forman parte de ese pluringüismo. El árabe clásico es la lengua oficial y constitucional del país y la lengua de la enseñanza. El amazigh fue reconocido en la última Constitución de 2011 como lengua oficial tras 
largas reivindicaciones para su reconocimiento. Su enseñanza se había iniciado antes de su reconocimiento como lengua oficial. En el curso académico 2003-2004 se ofertó en 319 colegios como asignatura obligatoria para todos los hablantes (Moustaoui, 2008: 12). No obstante, esta lengua aun no ocupa el lugar que le pertenece aunque lo hablan entre 15 y 20 millones de marroquíes según asociaciones amazigh y el $28 \%$ de la población del país según datos oficiales de 2006 (Llorent-Bedmar, 2014: 55). Sin embargo, el árabe marroquí sigue siendo invisible en la enseñanza marroquí. (Moustaoui, 2010:6).

El francés es lengua no oficial pero es el segundo idioma de enseñanza. En el sistema educativo privado el francés se enseña desde primaria junto con el árabe, e incluso en preescolar. A día de hoy se considera la lengua de la promoción social y de oportunidad de empleo, además del idioma de las carreras universitarias científicas. Actualmente, hay un debate abierto en Marruecos sobre si enterrar la arabización de la educación después de tres décadas, y optar por el francés como idioma de ciencias, o seguir con el modelo actual. El debate llegó hasta el Parlamento marroquí.

En 2018 el Consejo de Ministros marroquí aprobó el Proyecto Loi-Cadre n 51-17 para enseñar las asignaturas científicas en francés, desde la primaria hasta la enseñanza superior. Pero, el Proyecto de Ley fue bloqueado en el Parlamento por distintos partidos. Incluso el debate divide a la opinión pública marroquí.

El Ministro de Educación Said Amzazi subraya que el fracaso escolar y el abandono son a causa de uso del árabe como idioma de enseñanza de las asignaturas científicas, lo que dificulta el acceso a la universidad donde el idioma de enseñanza es el francés. Igualmente, en opinión del Ministro, la enseñanza en árabe dificulta el acceso al empleo. Los oponentes a este Proyecto de Ley consideran que su aprobación supondría la pérdida de la identidad.

En este panorama de la enseñanza de los idiomas, el español se enseña en el tercer y último curso de secundaria en los colegios públicos marroquíes ${ }^{46}$. Se implantó como optativa a partir del curso 2005-2006, junto al inglés, alemán, portugués o italiano, dos horas lectivas semanales (Amirah, 2015: 104). En realidad, en la mayoría de los centros se ofrece principalmente el inglés, como preferencia de los padres, lo que provoca que las otras lenguas tengan una presencia reducida (Ministerio de Educación, Cultura y Deporte, 2016: 42). Además de las salidas que ofrece el idioma inglés, tanto a nivel nacional como a nivel internacional.

Según la Consejería de Educación, en su Guía para profesores y docentes de 2016, la situación del español no se ha estabilizado todavía. A pesar del interés que existe por el español, su espacio parece ser el correspondiente a una tercera lengua extranjera, después del francés y el inglés. El número de centros de secundaria donde se imparte el español no llega al 10\%.

El español ha alcanzado una cifra considerable de alumnos; 18.642, pero hay que señalar que el número de centros en los que se oferta es todavía muy reducido, ya que se limita a 138 (Fernández Suzor, 2014:62). En la zona Norte, es donde más se opta por el español, con un número de 6281 de los cuales 4559 son de la región de Tánger-Tetuán (Fernández Suzor, 2014:63) ${ }^{47}$.

El español en bachillerato se oferta desde los años sesenta (Ministerio de Educación, Cultura y Deporte, 2016: 42) como lengua optativa junto con las lenguas mencionadas anteriormente. Se

\footnotetext{
${ }^{46}$ Hay que subrayar que el sistema educativo marroquí se divide en 6 años de primaria, 3 años de secundaria y 3 años de bachillerato.

${ }^{47}$ No existen datos actualizados. Los últimos datos encontrados son del año 2014.
} 
considera la tercera lengua extranjera, a mucha distancia del inglés (Zebda, 2018: 144). No obstante, en el Norte de Marruecos-antiguo Protectorado español- la presencia del español se sigue notando, aunque cada vez menos.

A través de la cooperación educativa hispano-marroquí, en 2015 se implantó el bachillerato internacional opción español, que cuenta solamente con 53 alumnos. Esta acción está emprendida por el Ministerio de Educación Nacional y de la Formación Profesional marroquí, como prueba, en dos regiones Tetuán-Tánger-Alhucemas y la región Oriental. Existe la opción "inglés", con 426 alumnos. Estas modalidades siguen siendo en prueba, a diferencia de opción "francés" que ya está implantada como mínimo en un centro de cada Región, con 85.000 alumnos de secundaria y 99.258 alumnos de bachillerato estudiando las materias científicas en francés.

España, a través de la Consejería de Educación, coopera en la elaboración de los programas y en la confección de los manuales de español bajo la supervisión del Ministerio de Educación Nacional y de la Formación Profesional de Marruecos, a través de las publicaciones y aportaciones de profesores e inspectores de español y de asesores lingüísticos. Al mismo tiempo, gracias a la cooperación entre ambos países a través de sus tratados y sus RAN, España colabora con el Ministerio de Educación de Marruecos en la formación de los futuros profesores de español, tanto de secundaria como de bachillerato a través del el Centro Pedagógico Regional (CPR) de Tánger actual CRMEF (Centro Regional de Oficios de la Educación y la Formación)- y de la Escuela Normal Superior (ENS) de Tetuán.

Por otra parte, las publicaciones, las actividades formativas y otras actuaciones mantienen en contacto permanente al profesorado y la inspección de español con la asesoría lingüística de la Consejería de Educación (Zebda, 2018, 145).

En resumidas cuentas, a pesar de que el español está implantado en el sistema educativo marroquí desde secundaria, su situación es preocupante. Aún siendo parte de la cultura de muchos marroquíes, sobre todo del Norte, se va perdiendo poco a poco a favor del francés o el inglés, a pesar de que el español está más presente en su día a día.

\section{La red de centros educativos españoles en Marruecos}

La acción educativa española está desarrollada por el Ministerio de Educación, Cultura y Deporte y se enmarca en Real Decreto 1027/1993, de 25 de junio, por el que se regula la acción educativa española en el exterior, parcialmente modificado y completado por el Real Decreto 1138/2002, de 31 de octubre, por el que se regula la Administración del Ministerio de Educación, Cultura y Deporte en el exterior. y tiene como objetivo la promoción y difusión de la lengua y la cultura españolas en el mundo, y de la cooperación internacional. En la actualidad el Ministerio está presente en más de 40 países a través de distintos programas, con un objetivo múltiple: por un lado, ofrecer enseñanzas regladas del sistema educativo español correspondientes a niveles no universitarios; por otro, organizar e impulsar la presencia española en el seno de otros sistemas educativos; y trabajar por la expansión y el fomento de la lengua y la cultura (Subdirección General de Promoción Exterior Educativa, 2015) ${ }^{48}$.

La Consejería de Educación tiene como misión principal fomentar las relaciones existentes entre los dos países en el ámbito educativo e incrementar las actuaciones bilaterales dentro del mismo y se encarga de la gestión de la red de los 11 centros educativos españoles que forman parte de los 22 centros de titularidad estatal española repartidos en siete países de tres continentes. De esos 11 centros, ocho se ubican en la zona norte de Marruecos - consecuencia de su origen en los anteriores colegios del Protectorado - dos en el centro y uno en el Sáhara Occidental, en El Aaiún. De los ocho centros del primer grupo, cinco están en solo dos ciudades: tres en Tetuán y dos en

\footnotetext{
${ }^{48}$ SUBDIRECCIÓN GENERAL DE PROMOCIÓN EXTERIOR EDUCATIVA, Guía para asesores en la Consejería de Educación ante la OCDE, UNESCO y Consejo de Europa, SECRETARÍA GENERAL TÉCNICA, 2015
} 
Tánger, en Alhucemas, Nador y Larache. En el centro-oeste, se encuentran los centros de Casablanca y de Rabat.

En los once centros de titularidad del Estado Español en Marruecos durante el curso 20182019 imparten clases 357 profesores a 4418alumnos. La red de centros se considera la presencia más significativa del Ministerio español de Educación, Cultura y Deporte en Marruecos (Fernández Suzor, 2014: 67).

Los estudios son los correspondientes a los programas oficiales del sistema educativo español, no obstante, se adaptan al contexto marroquí, como por ejemplo, la materia de Lengua y Cultura árabe es obligatoria para todos los alumnos desde educación infantil y el francés como optativa está presente en todos los centros.

Los colegios españoles a su vez entran en la política marroquí de privatización de la enseñanza. Desde la puesta en marcha de la Charte Nationale de l'Éducation et de la Formation adoptada en 2000, Marruecos está fomentando la enseñanza privada que está teniendouno éxito superior al esperado. El Estado apoya al sector privado porque este último ofrece un servicio que el Estado es incapaz de asumir integralmente. El Estado apoya la enseñanza privada para « alléger la pression sur l'école publique » (Felk, 2006: 24)

Hay una fuerte demanda en los colegios privados marroquíes, considerados para las familias como una garantía de futuro para sus hijos. Pero la realidad es otra, los colegios privados son un negocio financiado por fondos privados y con un objetivo exclusivamente lucrativo, además que no está controlada en absoluto por el Ministerio de Educación, ni los precios de matrícula, ni un control pedagógico serio. Además con muchas facilidades fiscales, políticas incitativas, marco legal flexible, ayuda en la búsqueda de fondos, etc (Aubry, 2014: 1) lo que ha creado un campo de oportunidades y de inversión lucrativa para un lobby vigilante y activo (Felk, 2006: 25).

Esta situación ha creado un sistema dual totalmente diferente entre la enseñanza pública y la enseñanza privada; en colegios privados marroquíes y también las misiones extranjeras francesas, belgas, inglesas, americanas o españolas. Este sistema dual provoca una injusticia social, económica, cultural, ya que los colegios privados solo los pueden pagar familias de un nivel medio-alto lo que provoca una segregación escolar y una mercantilización de la enseñanza que favorece su elitización: colegios públicos para familias de clase baja y colegios privados para familias de clase medio-alta.

Fig. 4: Evolución del alumnado y profesorado

de los Centros Docentes de Titularidad del Estado Español

\begin{tabular}{|c|c|c|c|c|c|c|c|c|c|}
\hline Curso & $2010-$ & $2011-$ & $2012-$ & $2013-$ & $2014-$ & $2015-$ & $2016-$ & $2017-$ & $2018-$ \\
2011 & 2012 & 2013 & 2014 & 2015 & 2016 & 2017 & 2018 & 2019 \\
\hline Alumnado & 4769 & 4729 & 4735 & 4525 & 4394 & 4345 & 4307 & 4384 & 4418 \\
\hline $\begin{array}{c}\text { Profesora } \\
\text { do }\end{array}$ & 347 & 352 & 351 & 347 & 346 & 347 & 351 & 349 & 357 \\
\hline $\begin{array}{c}\text { Asesores } \\
\text { técnicos }\end{array}$ & 8 & 8 & 6 & 6 & 5 & 5 & 7 & 7 & 7 \\
\hline
\end{tabular}

Fuente: Elaboración propia a partir de los datos de la Base de Datos del Ministerio de Educación y Formación Profesional http://www.educacionyfp.gob.es/servicios-al-ciudadano/estadisticas/exterior/accion1920.html [consulta: 11 de abril de 2021]. 


\section{Conclusión}

La cooperación educativa entre España y Marruecos ha evolucionado en las últimas décadas. Desde la firma del Tratado de Amistad, Buena Vecindad y Cooperación en 1991 se ha convertido en uno de los ámbitos de cooperación presentes en agenda bilateral, sobre todo en el marco de las Reuniones de Alto Nivel. Pese a ello no ha alcanzado el nivel de desarrollo deseado y estipulado en los acuerdos bilaterales que, por otra parte, no dejan de ser escasos. En los últimos 20 años sólo ha sido firmado un convenio en este ámbito -en 2012- y éste no aborda sólo el ámbito educativo, sino que también se refiere a otras materias como la cooperación deportiva o cultural.

La cooperación educativa hispano-marroquí se plasma fundamentalmente en la enseñanza del árabe y de la cultura marroquí en España y en la enseñanza del español en Marruecos, tanto a través de la red de centros educativos españoles desplegados en el país como en los centros públicos marroquíes.

Por un lado, la organización e implantación del Programa LACM en España, el escaso material docente, la inadecuación de los profesores adscritos al mismo así como el hecho de que sea el árabe clásico el idioma de enseñanza explican el desinteres y la escasa participación del alumnado de origen marroquí en el mismo.

Por otro lado, ni la implantación del español en el sistema educativo marroquí desde la enseñanza secundaria ni la existencia de una extensa red de centros educativos españoles en Marruecos han conseguido impulsar el interés del alumnado para cursar la lengua española, idioma habitual en la zona norte del país, antiguo Protectorado español, en comparación con otros idiomas extranjeros como el francés o el inglés.

\section{Referencias}

AMIRAH FERNANDEZ, Haizam (2015): Relaciones España-Marruecos, (coord.), Informe Elcano 19, Real Instituto Elcano, disponible en http://www.realinstitutoelcano.org/wps/portal/rielcano es/publicacion?WCM_GLOBAL_CONTEXT =/elcano/elcano es/publicaciones/informe-elcano-19-relaciones-espana-marruecos [consulta: 15 de marzo de 2019].

ARIAS, Juan Pablo (1999): "Profesores al borde de un ataque de nervios: didáctica del árabe para escolares inmigrantes", en FRANZÉ, Adela y MIJARES, Laura (Eds.): Lengua y cultura de origen: niños marroquíes en la escuela española, Madrid, Ediciones del Oriente y del Mediterráneo, pp. 201-211.

AUBRY, Sylvain, (2014): "Privatisation dans l'éducation au Maroc et droit à l'éducation: fiche résumé visuelle", Informe de Global Economic, Social and Cultural Rights, disponible en https://anfass.ma/wp.../01/Rapport-CESCR-Maroc-privatisation-éducation-final.pdf [consulta: 17 de febrero de 2020].

BAKER, Colin (1997): Fundamentos de educación bilingüe y bilingüismo, Madrid, Cátedra.

BEN EL AMIN, Boutaina, (2015): “La presencia educativa española en el Protectorado del norte de Marruecos", Actas del I Congreso de español como lengua extranjera del Magreb "La enseñanza del español en el Magreb: oportunidades y retos», Rabat, 11-12 de diciembre, Insituto Cervantes, Rabat, pp. 129-133, disponible en https://cvc.cervantes.es/ensenanza/biblioteca ele/publicaciones centros/PDF/rabat 2015/22 be

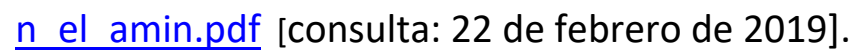


BENYAYA, Zineb (enero 2007): "La enseñanza del español en Marruecos: del pasado al presente", PORTA LINGUARUM no 7, pp. 167-180, disponible en https://digibug.ugr.es/bitstream/handle/10481/31607/Benyaya.pdf?sequence=1\&isAllowed=y [consulta: 31 de abril de 2019].

DARANAS PELÁEZ, Mariano (2011): “Constitución del Reino de Marruecos", Revista de las Cortes Generales, no 82, pp. 481-561. DOI: https://doi.org/10.33426/rcg/2011/82/362

DEL VALLE GÁLVEZ, José Alejandro y TORREJÓN RODRÍGUEZ, Juan Domingo (2013): España y Marruecos tratados, declaraciones y memorandos de entendimiento (1991-2013), Cádiz, Sevicio de Publicaciones de la Universidad de Cádiz.

Embajada del Reino de Marruecos en Madrid (2009). Programa hispano-marroquí de Enseñanza de la Lengua Árabe y la Cultura Marroquí, disponible en https://www.berrigasteiz.com/site argitalpenak/docs/120 diversidad/1202015001 Pub MEC co nvenio lacm.pdf [consulta: 15 de junio de 2019].

EL HOUDAIGUI, Rachid (2003): La politique étrangère sous le règne de Hassan II. Acteurs, enjeux et processus décisionnels. Paris, L'Harmattan.

FELK, Abdellatif (2006): "Enseignement et éducation au Maroc", AFKAR/IDEAS, pp. 23-26, disponible en https://www.iemed.org/observatori/arees-danalisi/arxiusadjunts/afkar/afkar ideas 9/grand_angulaire enseignement education Maroc Abdellatif_Felk_a fkar9.pdf [consulta: 3 de marzo de 2019].

FERNÁNDEZ SUZOR, Cecilia (1993): "Los centros culturales y el Instituto Cervantes en Marruecos", en MORALES LEZCANO, Víctor (coord.) Presencia cultural de España en el Magreb: pasado y presente de una relación cultural "sui generis" entre vecinos mediterráneos, Madrid, Fundación MAPFRE, pp. 169-174, disponible en http://www.larramendi.es/es/consulta/registro.do?id=9918 [consulta: 11 de abril de 2021].

FERNÁNDEZ VÍTORES, David (2004): La Lengua española en Marruecos, Rabat, Embajada de España, disponible

http://www.exteriores.gob.es/Embajadas/RABAT/es/Noticias/Documents/LENGESPMARR.pdf [consulta: 10 de abril de 2019].

GARCÍA, Rosa (1999): "Educar en la diversidad. Experiencia en el colegio "Antonio Moreno Rosales", en FRANZÉ, Adela y MIJARES, Laura (Eds.): Lengua y cultura de origen: niños marroquíes en la escuela española, Madrid, Ediciones del Oriente y del Mediterráneo, pp. 165-167.

GONZALEZ BRIONES, Elena (2009): Guía Práctica del profesorado de la Lengua árabe y Cultura Marroquí, Madrid, Ministerio de Educación, Cultura y Deporte, disponible en http://sede.educacion.gob.es/publiventa/guia-practica-del-profesorado-de-lengua-arabe-ycultura-marroqui/lengua-arabe-cultura-marruecos/12638 [consulta: 22 de marzo de 2019].

GONZÁLEZ DEL MIÑO, Paloma (2005): Las relaciones entre España y Marruecos. Perspectivas para el siglo XXI, Madrid, Catarata.

GONZÁLEZ GONZÁLEZ, Irene (2011): "La política educativa española en el Norte de Marruecos (1869-1912), en MARTíNEZ ANTONIO, Francisco Javier y GONZÁLEZ GONZÁLEZ, Irene, Regenerar España y Marruecos: ciencia y educación en las relaciones hispano-marroquíes a finales del siglo XIX, Madrid, Consejo Superior de Investigaciones Científicas. pp. 219-252 
HERNANDO DE LARRAMENDI, Miguel y MAÑÉ, Aurelia (eds.) (2009): La política exterior española hacia el Magreb. Actores e intereses, Barcelona, Ariel/Real Instituto Elcano.

LLORENT-BEDMAR, Vicente (2014): "Identidad cultural bereber y enseñanza del amazigh", Revista española de educación comparada, no 23, pp. 53-75. DOI: https://doi.org/10.5944/reec.23.2014.12297

MEZIANE BELFKIH, Abdelaziz (2000) : "La Charte Nationale d'éducation-formation. Une ambition pour l'école au Maroc ", Revue internationale d'éducation de Sèvres, no 27. pp. 77-87. DOI: https://doi.org/10.4000/ries.2383

MIJARES MOLINA, Laura (2005): “Inmigración en la escuela española: programas de mantenimiento de las lenguas de origen", Anales de Historia Contemporánea, no 21. pp. 111-124, disponible en https://revistas.um.es/analeshc/article/view/55021/53011 [consulta: 22 de febrero de 2019].

MIJARES MOLINA, Laura (2005a): "El Programa ELCO marroqui", en (Coord), FERNANDEZ GARCIA, Tomás. GARCIA MOLINA, José, Multiculturalidad y educación : teorías, ámbitos y prácticas, Madrid, Alianza, pp. 334-352, https://dialnet.unirioja.es/descarga/articulo/1186379.pdf [consulta: 5 de abril de 2019].

MIJARES MOLINA, Laura (2006): Aprendiendo a ser marroquíes. Inmigración, diversidad lingüística y escuela, Madrid, Ediciones del Oriente y del Mediterráneo.

MIJARES MOLINA, Laura (2006a): "Inmigración y reconocimiento lingüístico", Afkar/ldeas, no 9, pp. 35-36, disponible en https://www.politicaexterior.com/articulos/afkar-ideas/inmigracion-yreconocimiento-linguistico/ [consulta: 18 de abril de 2019].

MIJARES MOLINA, Laura y MARTIN ROJO, Luisa (2007): “"Sólo en español»: una reflexión sobre la norma monolingüe y la realidad multilingüe en los centros escolares", Revista de Educación, no 343, pp. 93-112, disponible en https://pdfs.semanticscholar.org/2e56/09e5f03c74c410cf51a6cd2196816ebc5ff0.pdf? ga=2.1210 37512.1346536791.1584270687-1678334332.1584270687 [consulta: 18 de abril de 2019].

MOSCOSO GARCÍA, Francisco (2013): “El programa hispano-marroquí de enseñanza de Lengua Árabe y Cultura Marroquí (LACM) sometido a revisión, Árabe marroquí y amazige, lenguas nativas (L1)", Anaquel de Estudios Árabes, no 24, pp. 119-135. DOI: https://doi.org/10.5209/rev_ANQE.2013.v24.42631

MOUSTAOUI SRHIR, Adil (2008): "El Movimiento Cultural Amazigue en Marruecos y el modelo de política lingüística estatal: una aproximación discursiva", REIM, no5, pp. 5-26, disponible en https://revistas.uam.es/index.php/reim/article/download/773/761 [consulta: 12 de febrero de 2019].

MOUSTAOUI, Adil (2010): “¿Implementando el monolingüismo o el multilingüismo?: Política lingüística y Estado-nación en Marruecos a raíz de los nuevos cambios", REIM, no9, pp. 1-17, disponible en https://revistas.uam.es/index.php/reim/article/download/837/825 [consulta: 15 de marzo de 2018].

NECHDA, Mohamed (1999): "La enseñanza de la Lengua Árabe y Cultura Marroquí (LACM) en España”, en FRANZÉ, Adela y MIJARES, Laura (Eds.): Lengua y cultura de origen: niños marroquíes en la escuela española, Guadarrama, Ediciones del Oriente y del Mediterráneo, pp. 179-181.

PLANET, Ana I. y HERNANDO DE LARRAMENDI, Miguel (2005): “Una piedra en el camino de las relaciones hispano-marroquíes: la crisis del islote Perejil" en PLANET Ana I. y RAMOS, Fernando (eds): Relaciones hispano-marroquíes. Una vecindad en construcción, Guadarrama, Ediciones del Oriente y del Mediterráneo, pp. 403-430. 
REVILLA CASTAÑO, Irene y VÍLCHEZ DE ARRIBAS, Manuel (2006): “La Consejería de Educación en Marruecos", Aljamia, no 17, pp. 47-52.

RICHTERS, Judith (1999): "La ELCO en Holanda. Dos modelos: el modelo actual y el modelo futuro", en FRANZÉ, Adela, y MIJARES, Laura (Eds.): Lengua y cultura de origen: niños marroquíes en la escuela española, Madrid, Ediciones del Oriente y del Mediterráneo, pp. 103-113.

ROLDÁN ROMERO, Magdalena, (2006): “El español en el contexto sociolingüístico marroquí: evolución y perspectivas (II)", Aljamía, no 17, pp. 25-37, disponible en https://sede.educacion.gob.es/publiventa/descarga.action?f_codigo_agc=13438 19 [consulta: 29 de abril de 2019].

SUBDIRECCIÓN GENERAL DE PROMOCIÓN EXTERIOR EDUCATIVA (2015): Guía para asesores en la Consejería de Educación ante la OCDE, UNESCO y Consejo de Europa, SECRETARÍA GENERAL TÉCNICA, Subdirección General de Documentación y Publicaciones, disponible en https://sede.educacion.gob.es/publiventa/descarga.action?f_codigo agc=17213 [consulta: 15 de febrero de 2019].

TORREJÓN RODRIGUEZ, Juan Domingo y ZEBDA Siham (2013): “Reunión de Alto Nivel EspañaMarruecos, Rabat, Octubre 2012", Paix et Sécurité Internationales, no 1, pp. 177-201. DOI: https://doi.org/10.25267/Paix secur int.2013.i1.13

ZEBDA, Siham (2015): "XI Reunión de Alto Nivel Hispano-Marroquí, julio de 2015: reflexiones sobre la cooperación en economía, seguridad y cultura", Paix et Sécurité Internationales, no3. pp. 227-237. DOI: https://doi.org/10.25267/Paix secur int.2015.i3.12

ZEBDA, Siham (2018): “La enseñanza del español en Marruecos”, Ateneo, no18, pp. 141-148. 